$4^{\text {th }}$ International Meeting on Calcitonin Gene-Related Peptide (CGRP)

TheScientificWorld (2001) 1(S1), 22

ISSN 1532-2246; DOI 10.1100/tsw.2001.439

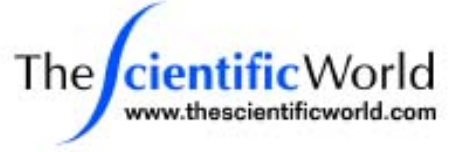

\title{
ALTERED NEUROADAPTATION IN OPIATE DEPENDENCE AND NEUROGENIC INFLAMMATORY NOCICEPTION IN $\alpha$ CGRP DEFICIENT MICE
}

\author{
A.-M. Salmon, I.M. Damaj, L.M.Marubio, M.P. Epping-Jordan, E. Merlo Pich, and J.-P. \\ Changeux \\ Institut Pasteur, Neurobiologie Moleculaire-Biotechnologie, 25 Rue du Dr. Roux, 75015 Paris, \\ France
}

$\alpha$ CGRP is expressed in a variety of cell types in both central and peripheral nervous system[1]. Among its various functions, it is involved in the complex process of pain signaling[2,3]. Yet, the precise contribution of $\alpha$ CGRP is still unclear.

Using $\alpha$ CGRP deficient mice (-/-), we show that the lack of $\alpha$ CGRP underlies an attenuated response to chemical pain and inflammation[4]. In other words, $\alpha$ CGRP is critical for the production and, possibly, the transmission of pain signals associated with neurogenic inflammation. Furthermore, $\alpha$ CGRP -/- mice present a reduction in the antinociceptive response to morphine, indicating a modulatory role (agonist) of $\alpha$ CGRP in opioid pathways[5]. In contrast, the antinociceptive response to nicotine is potentiated, showing a negative modulation of $\mathrm{nAChR}$ function by this neuropeptide[4]. Thus, $\alpha$ CGRP has a complex role in the modulation of analgesic drug pathways.

Moreover, $\alpha$ CGRP -/- mice do not show changes in morphine self-administration and tolerance, but display a marked decrease in morphine withdrawal signs[4]. We suggest that aCGRP may influence the contribution of peripheral signals to the aversive emotional state occurring in the opiate dependence syndrome.

Taken together, these results show that $\alpha$ CGRP plays a critical role in mediating both chemical inflammatory pain and sensitivity to morphine withdrawal. Antagonists of $\alpha$ CGRP may thus offer novel therapeutics for the treatment of pain and drug addiction.

\section{REFERENCES}

1. Rosenfeld, M.G., Amara, S.G., and Evans, R.M. (1984) Science 225, 1315-1320.

2. Hughes, S.R. and Brain, S.D. (1991) J. Pharmacol. 104, 738-742.

3. $\quad$ Gibbins, I.L., Furness, J.B., and Costa, M. (1987) Cell Tissue Res. 248, 417-437.

4. $\quad$ Salmon, A.M. et al. (2001) Nature Neurosci. 4, 357-358.

5. Salmon, A.M. et al. (1999) NeuroReport 10, 849-854. 

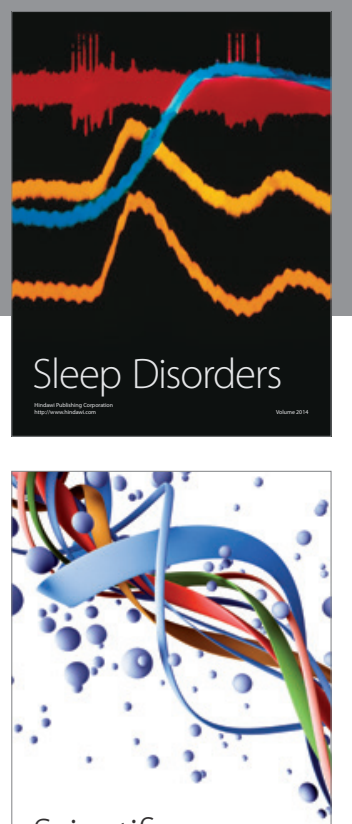

Scientifica
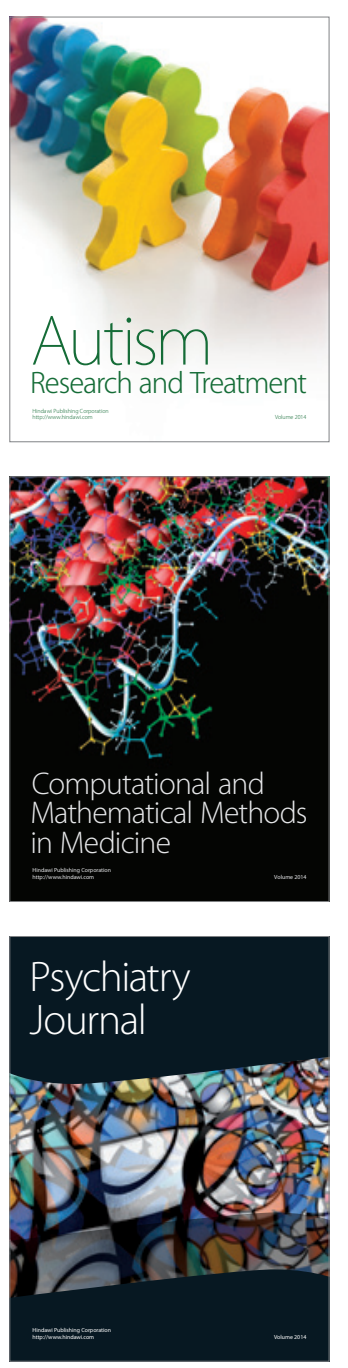
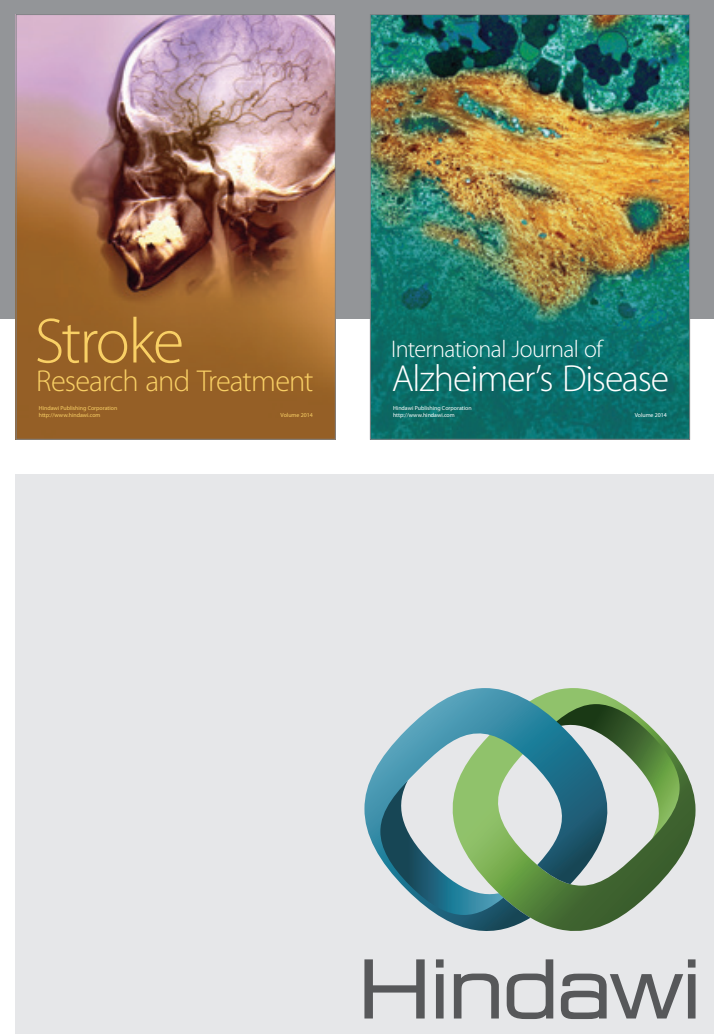

Submit your manuscripts at

http://www.hindawi.com
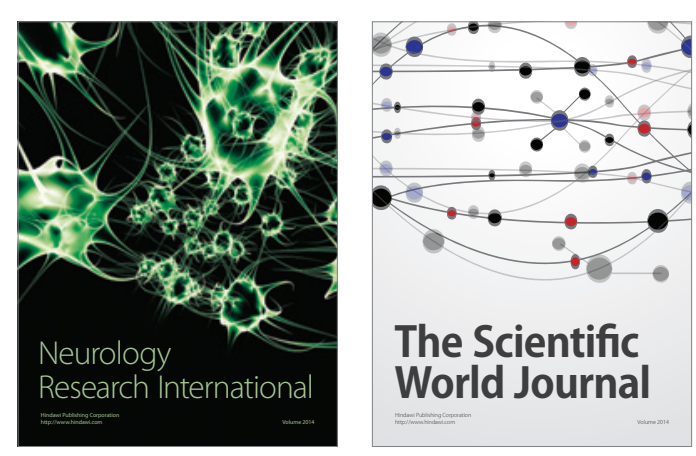

The Scientific World Journal

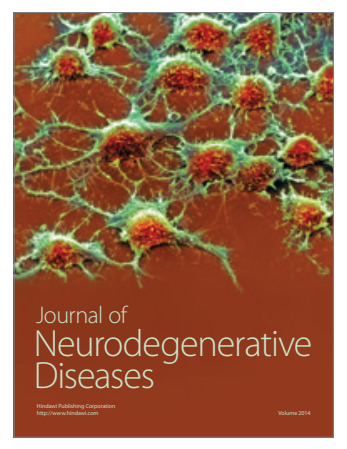

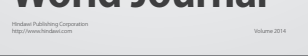

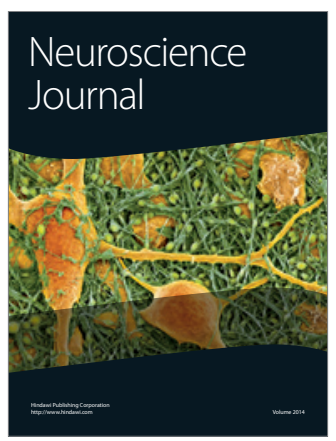

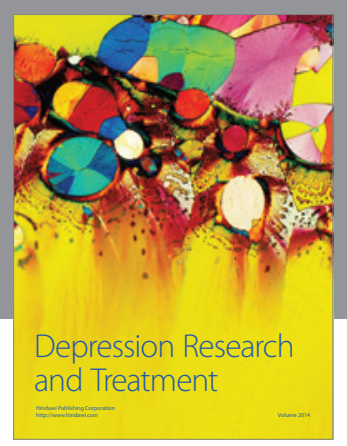
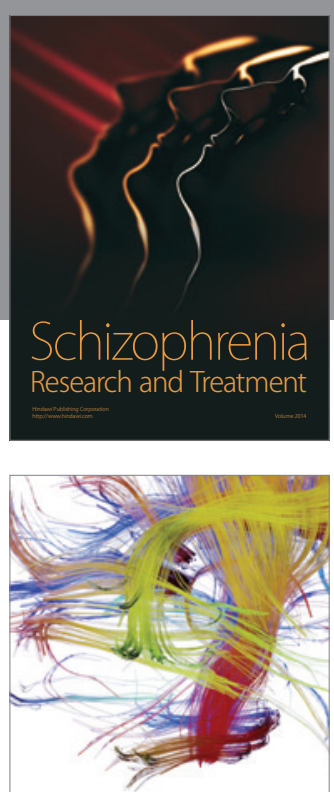

Brain Science

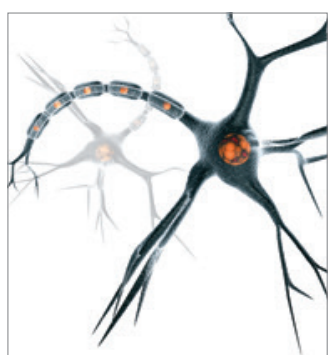

Neural Plasticity
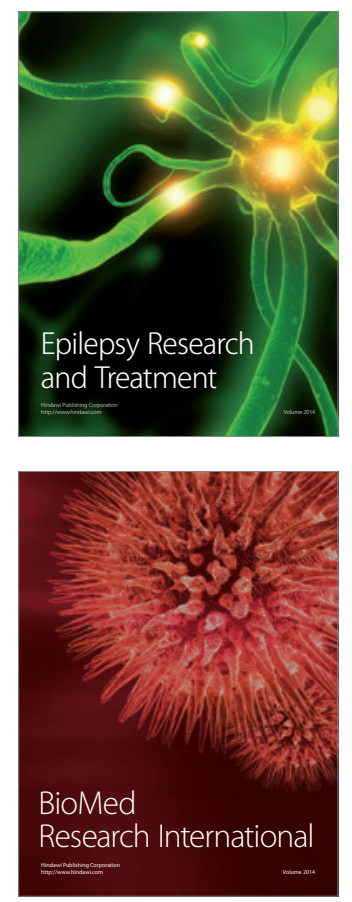

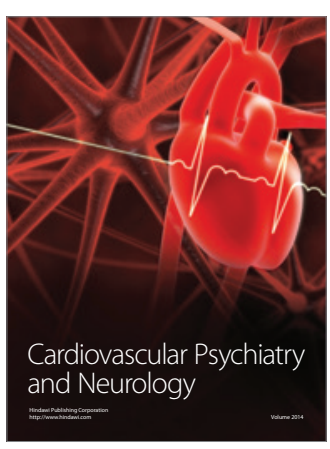

Parkinson's

Disease
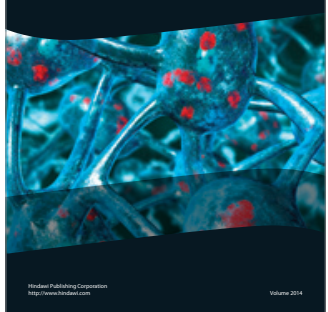